\title{
Survivors' Experiences of Intimate Partner Violence and Shelter Utilization During COVID-19
}

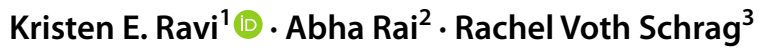 \\ Accepted: 21 June 2021 / Published online: 30 June 2021 \\ (c) The Author(s), under exclusive licence to Springer Science+Business Media, LLC, part of Springer Nature 2021
}

\begin{abstract}
This paper examines the effects of COVID-19 on service-engaged female survivors of IPV and makes recommendations for service providers based on these survivors' voices. The researchers adopted an exploratory, descriptive, and qualitative approach to inquiry due to the novelty of the research questions during the early days of the COVID-19 in March 2020. Semistructured interviews with service-engaged survivors were analyzed using inductive and deductive coding processes. Two categories arose from our qualitative questions. The first category, related to experiences with service providers, included the themes of varying levels of support and isolation. Within the theme of isolation, survivors discussed both positive and negative aspects of isolation. The second category refers to the impact of COVID-19 on survivors' daily lives and focused on the theme of escalation. The theme of escalation had two subthemes 1) escalation of life-generated risks and 2) escalation of partner-generated risks. Given that the pandemic will continue until vaccines are fully distributed and that future public health emergencies may mirror many of the challenges identified in the current context, survivors residing at home will continue to need services, and agencies will continue to need additional resources to provide them. Therefore, we discuss recommendations that can have a bearing on services offered in the future.
\end{abstract}

Keywords COVID-19 $\cdot$ Intimate partner violence $\cdot$ Domestic violence $\cdot$ Qualitative

COVID-19 is a deadly pandemic that has claimed several hundred thousand lives in the United States and worldwide. As of June 16, 2021, 600,648 people have died from COVID-19 in the United States (Johns Hopkins University and Medicine Coronavirus Resource, 2021). In addition to the devastating health consequences, COVID-19 has had catastrophic effects across sectors, including the economy, employment, and education. The unemployment rate peaked at $15.1 \%$ in the second quarter of 2020 . The Congressional Budget Office (2020) has projected that the unemployment rate will decline but will still be elevated through 2021 at approximately $9.3 \%$. However, vaccines are becoming increasingly available to the public, potentially mitigating some of the associated risks allowing individuals to return

Kristen E. Ravi

Kravi2@utk.edu

1 The University of Tennessee-Knoxville, 1618 Cumberland Ave, Knoxville, TN 37996, USA

2 Loyola University Chicago, Chicago, IL, USA

3 University of Texas At Arlington, Arlington, TX, USA to work. This study aims to discuss the impact of COVID19 on female survivors' experiences of violence and IPV services.

The stay-at-home orders that began in March 2020 (Mervosh et al., 2020) have inevitably forced survivors of violence to remain confined with their abusive partners for extended periods. This prolonged time spent together may be dangerous for current and potential victims of IPV, as being trapped with an abusive partner intensifies the isolation of survivors from social supports outside of their home and limits access to possible avenues for support or safety (Campbell, 2020; Fernandes-Alcantara \& Sacco, 2020; Rai et al., 2020; Wood et al., 2021). In addition, the confinement may cause distress for survivors and potentially re-traumatize survivors who have experienced trauma related to IPV (Southhall, 2020) or lead to increased instances of IPV in the absence of access to safe shelters or key informal supports like friends or family members (Anurudran et al., 2020). A recent systematic review demonstrated that IPV increased in response to the stay-at-home orders (Piquero et al., 2021). IPV help-seeking during the pandemic has varied by location. Early in the pandemic urban areas saw an increase in 
police IPV calls, IPV hotline calls, and orders of protection sought (Avila \& Cardenas, 2020; Salazar, 2020), while helpseeking decreased in rural areas (Avila \& Cardenas, 2020). This decrease in IPV help-seeking in rural areas does not necessarily indicate a reduction in incidents; instead, it may indicate survivors having less opportunity to seek help when constantly home with an abusive partner, especially in rural areas with limited options for services, geographic distances, and public transportation (Avila \& Cardenas, 2020; Ortegon $\&$ Proctor, 2020). Additionally, the initial uptick in calls to the police early in the pandemic did not last, highlighting how access to technology, such as cellphones, could be an issue (Nix and Richards, 2021; Piquero et al., 2020).

Given how IPV disproportionately impacts women, our study focused on female IPV survivors. Through semistructured interviews, this paper examines the effects of COVID-19 on service-engaged female survivors of IPV. Understanding the lived-experiences of survivors experiencing IPV during the COVID-19 pandemic could inform service providers about how to best support survivors living in shelters and engage in safety planning with survivors in the community during this and future public health emergencies. These findings can have implications for the future as the pandemic still unfolds and inform future public health emergencies and disasters.

\section{Intimate Partner Violence and COVID-19}

The Centers for Disease Control and Prevention (Centers for Disease Control and Prevention, 2018) define IPV as physical violence, sexual violence, stalking, and psychological aggression (including coercive acts) by a current or former intimate partner. Approximately one in four women and one in ten men in the United States are survivors of severe physical violence, sexual violence, or stalking by an intimate partner (CDC, 2018). An estimated 43 million American women and 38 million men have experienced psychological IPV in their lifetime (CDC, 2018).

While variations in IPV prevalence rates during COVID19 are still being uncovered, Davis et al. (2020), in their national study with 2,045 individuals, found that men were two times more likely to use physical violence than women. With conditions for increasing IPV cases created by stayat-home orders, understanding the experiences of survivors engaged in accessing services was important. In addition to the stress directly related to health due to COVID-19, families are experiencing additional strain due to increased unemployment, reduced income, lack of social support, disruptions in schooling and childcare, and limited resources. These factors have been found to have increased the likelihood of IPV (Campbell, 2020; Davis et al., 2020; Moreira \& Pinto de Costa, 2020).
These stressors, especially job loss and economic insecurity, may be a catalyst for relationships that are at-risk for IPV to escalate to violence (Anurudan et al., 2020). In combination with the stress of forced coexistence during COVID-19 lockdowns, the presence of financial insecurity further triggers additional factors of stress in households (Arenas-Arroyo et al., 2020). Pre-COVID-19 research shows that economic stress is associated with a higher risk of victimization of women and IPV perpetration by men and that lower socioeconomic status also increases the frequency and severity of IPV (Davies et al., 2015; World Health Organization, 2012). Additionally, individuals of lower socioeconomic status lack the same resources available to those of higher status. Therefore, they are more likely to be in a relationship characterized by economic co-dependence and shared resources, which can lead to increased difficulty in leaving the relationship (Goodman et al., 2009). Further, Black, Indigenous, Multiracial, People of Color (BIMPOC) women may be at a higher risk of experiencing IPV during the pandemic, as many employers have displaced women and Black/African American, Latinx, and Indigenous individuals at a disproportionately high rate (Kantamneni, 2020; Neeley, 2020). Black/African American, Latinx, and indigenous individuals tend to be underrepresented in professional occupations that allow for more work-from-home opportunities, and they may face even further economic consequences (Kantemneni, 2020; Bureau of Labor Statistics, 2020).

Other vulnerable populations at a higher risk for IPV include lesbian, gay, bisexual, and transgender individuals. Individuals in a same-sex relationship are at a higher risk for IPV compared to individuals in other-sex relationships (Kozuch, 2020; Longobardi \& Badenes-Ribera, 2017). Transgender individuals are 1.7 times more likely to experience any IPV and twice as likely to experience physical or sexual IPV compared to cisgender individuals (Peitzeier et al., 2020).

Abusive partners use various tactics to isolate their partner from social support networks, including friends and family, as a means to increase control over their partner and limit their partner's access to external support, ultimately enhancing risks of victimization (Guerra, 2018). Further, abusive partners may capitalize on the economic and other uncertainties related to the COVID-19 pandemic by increasing controlling behaviors, such as preventing their partner from leaving the house or threatening not to let them into the house when they return (Godin, 2020). While these behaviors may be presented as an effort to curtail the spread of the virus, they can easily be used as coercive control mechanisms by abusers to limit the movement of their partners. Abusive partners also may weaponize COVID-19 by forbidding their partners to wash their hands or take other protective measures to increase their partner's fear of the virus or by withholding treatment if their partner experiences 
symptoms (Campbell, 2020; Fernandes-Alcantara \& Sacco, 2020). Therefore, in our study, we utilize Davies and Lyon's (2014) framework of Victim Defined Advocacy to examine both life and batterer-generated risks and how they impact survivors' IPV experiences during COVID-19.

Further, evidence related to the impacts of COVID-19 on IPV service utilization is conflicting. Some research indicates that IPV service utilization has decreased (FernandesAlcantara \& Sacco, 2020). Practitioners and scholars have posited that, by being close to their abusive partners around the clock, IPV survivors may have limited opportunities to utilize IPV crisis helplines or shelters due to fear of repercussions (Fernandes-Alcantara \& Sacco, 2020). This assertion is supported by Leat (2021), who found in her qualitative study of IPV shelter employees that the number of clients living in the shelter has decreased dramatically, in part due to social distancing requirements. However, other evidence suggests that IPV hotline calls are increasing and that shelters report being at capacity (Fernandes-Alcantara \& Sacco, 2020; Godin, 2020).

Similarly, law enforcement officers have reported a substantial increase in calls related to IPV (Boserup, 2020; Fernandes-Alcantara \& Sacco, 2020). Previous research has also indicated that shelters in the U.S. may replicate the abusive dynamics that survivors aim to leave behind when fleeing an abusive relationship, such as isolation from their friends and family members, which can cause further distress to those individuals (Glenn \& Goodman, 2015). Given the unfolding nature of the COVID-19 pandemic and the need to understand the perspectives of survivors in this context, to develop effective community responses within the current disaster response and for future public health emergencies, the purpose of this study is to understand the livedexperiences of the impact of the COVID-19 pandemic on IPV among service-engaged female survivors and to make recommendations for service providers based on these survivors' voices.

\section{Theoretical Framework: Victim Defined Advocacy}

Davies and Lyon (2014) highlight the importance of advocates understanding the risks facing survivors of IPV, both those created by their abusive partner and those created by other life circumstances, to better plan the process of safety planning and advocacy. In their approach to victim defined advocacy, they focus on: (a) life generated risks (i.e., factors such as limited English ability, experiences of racism, or structural poverty, that are external to but build upon and compound the violence within intimate relationships), and (b) batterer generated risks (i.e., risks created explicitly by an abusive partner, such as the risk of physical or sexual violence), which work in combination to influence survivors' ongoing safety planning and analysis, and the types of interventions that will be effective and necessary.

Victim-defined advocacy suggests that it is the job of advocates to join survivors in this ongoing safety planning and to acknowledge that there may be substantial life generated risks (such as poverty, housing instability, or experiences of racism) that may strongly influence the choices women make concerning their relationships and their ongoing evaluation of the safest options for themselves and their children. This framework was useful to understand survivors' experiences regarding the impact of COVID-19 on IPV.

\section{Methods}

This study was conducted at the beginning of the pandemic in March 2020. The researchers adopted an exploratory, descriptive, and qualitative approach to inquiry due to the novelty of the COVID-19 pandemic and survivors' experiences at that time. This study was a part of a broader mixed-methods study that aimed to validate a transportation coercion measure with survivors of IPV that included questions related to survivors' experiences of partner-related transportation coercion-which we defined as partnerrelated barriers to transportation. Part of the semi-structured interview included questions and prompts related to how COVID-19 affected survivors' experiences of violence and experiences with accessing transportation while living in the shelter service providers' role in providing transportation. All researchers were trained in qualitative research and have practice and research knowledge of IPV survivors and services, enhancing data collection and the data analysis process. Participants were recruited from two IPV service agencies in a single state in the Southwestern United States. Inclusion criteria were: being over the age of 18 , having experienced IPV within the last 12 months, and either residing in the IPV shelter or receiving services from the IPV service agency.

\section{Participants}

The participants in the study were ten female survivors of IPV who were receiving services from either an urban $(n=5)$ or a rural IPV service agency $(n=5)$. The participants' ages ranged from 19-44 years old. Half of the participants identified as White, and the other half identified themselves as Black $(n=3)$, Latinx $(n=1)$, or Multiracial $(n=1)$. The majority of the participants identified as heterosexual $(n=8)$, while two identified as bisexual. Half $(n=5)$ of the participants were currently not working but were actively seeking employment. Two participants were 
out of work and stated they were not seeking employment. Two were employed for wages or self-employed, and one participant reported that she was unable to work. Eight of the survivors were living in an emergency IPV shelter, one participant reported living in a relative's home, and one was living in transitional housing. The researchers did not have any relationships with the participants before conducting the study.

The researchers for the larger study worked with agency leadership to distribute study promotional material, including flyers posted in the agencies and at the IPV shelters. A convenience sample was used. Participants contacted the research team by phone and were provided with additional information about the study. All activities were approved by the Institutional Review Board of [Blinded] University prior to the beginning of data collection.

\section{Data Collection}

The researchers obtained a waiver of written informed consent and were approved to document verbal consent to help protect the safety of the participants. All interviews were conducted over the phone at a time that the participants selected. Participants were selected to protect their identity and were asked not to use their real names or their children's names. If any identifying information was accidentally provided, such as referring to a specific location, the data were deidentified after receiving the transcripts from the transcription company.

The first author interviewed the 10 participants, who were asked to reflect on the following question "To what extent has COVID-19 affected your experience of domestic violence and your ability to use transportation?". The proportion of the COVID-19 discussion was approximately a quarter of the interview; however, it varied based on the length of the participants' answers. In some cases, another question in the interview guide that referred to the survivors' experiences with service providers responding to transportation needs prompted discussion about how COVID-19 affected service providers' ability to provide transportation during the stay-at-home orders. A followup prompt was used to ask the participant how service providers responded when the participant asked to leave the shelter. Additionally, participants were asked how they overcame challenges related to COVID-19. Participants were given a \$20 Walmart gift card as a "thank you" for participating in the study. The gift card was either emailed to the participant or to their case manager in case they chose the electronic option, or it was mailed to the shelter administrative offices in case they opted for the paper version.

\section{Data Analysis}

The researchers utilized thematic analysis (Braun \& Clarke, 2006) to understand the survivors' experiences. After obtaining verbal consent with explicit permission to be audiotaped, the first author audio-recorded the interviews. The full interview lasted approximately $30-45 \mathrm{~min}$. The researcher immediately deleted the audio recording from the recording device after uploading it to a password-protected encrypted server. A professional transcription company trained in confidentially securing data transcribed all of the interviews. The first author did not follow up with participants for memberchecking because identifying information was not collected due to concerns about survivor safety.

Detailed audit trails and notes were maintained throughout the process of data collection and coding. The first and second authors read the transcripts multiple times and coded them independently using inductive and deductive coding (Saldaña, 2013). The authors met to discuss the codes they created. The authors inductively coded the data related to experiences with IPV services and deductive coded using Davies and Lyon's (2014) framework to code survivors' experiences of IPV. Once consensus was reached on the preliminary coding structure, the authors independently identified themes and met 4-5 times to discuss the themes that they identified until consensus was reached through an iterative process of refining the themes and subthemes (Braun and Clarke, 2006). The first author created a codebook that named and defined the agreed-upon themes with exemplar quotes, and the third author reviewed the interview transcripts and codebook. The third author provided feedback and suggestions to revise the codebook based on her expertise in IPV, given her 15 years of practice and research experience with survivors and of working with shelters. After receiving input from the third author, the first author re-coded the data using the revised codebook, and the author team agreed upon a final structure.

Through the audit trails and multiple author meetings, we ensured that the trustworthiness in the analysis was ensured throughout. An audit allows researchers the opportunity to systematically document choices made by researchers regarding theoretical and methodological issues, decisions, and the rationale for such decisions (Elo et al., 2014; Koch, 1994; Nowell et al., 2017). In describing our process of data collection and analysis with precision, we hoped to leave a clear "decision trail" (Koch, 1994, p.3). The researchers included the exact words of the survivors wherever possible to maximize the inclusion of survivors' voices. The authors made notations where small changes were made for narrative flow. Additional contextual information was included for a theme or quotation if it did not jeopardize the survivor's anonymity. We used the recommendations included in the Journal Article Reporting Standards (JARS) as a framework 
to provide a detailed explanation of our study procedures and to ensure transparency (Elo et al., 2014; Levitt et al., 2018).

\section{Results}

The findings of this study are presented based on two categories that arose from our qualitative questions. A breakdown of categories, themes, and sub-themes is included in Table 1 and frequencies in Table 2. The first category related to experiences with service providers and included the themes: 1) varying levels of support and 2) isolation. The second category refers to the impact of COVID-19 on their daily lives. The main theme that emerged from the analysis process under this category was escalation which had two subthemes that included: 1) escalated life-generated risks, and 2) escalated partner-generated risks. They were coded deductively using Davies' (2017) survivor risk analysis framework.

\section{Category I: Experiences with Services}

In sharing their experiences of the COVID-19 pandemic, participants elaborated upon their experiences with service providers and their access to services. Participants experienced varying levels of support and isolation. These themes will be described below.

Theme 1: Varying levels of support Survivors generally recognized that agencies are facing unique challenges as they seek to adapt to social distancing and other COVID19 precautions. Five participants both from rural and urban shelters described supportive experiences with service providers in the context of the COVID-19 pandemic. Michelle, a participant from an urban shelter, described how services
Table 2 Frequency of themes

\begin{tabular}{llll}
\hline Category & Theme & Subtheme & Frequency \\
\hline $\begin{array}{l}\text { Experiences } \\
\text { with }\end{array}$ & $\begin{array}{c}\text { Varying } \\
\text { levels of }\end{array}$ & & $\mathrm{n}=7$ \\
$\begin{array}{l}\text { service } \\
\text { providers }\end{array}$ & support & & \\
& Isolation & & $\mathrm{n}=7$ \\
$\begin{array}{l}\text { Impact of } \\
\begin{array}{l}\text { COVID- } \\
19 \text { on } \\
\text { daily lives }\end{array}\end{array}$ & $\begin{array}{c}\text { Escalation } \\
\text { Escalated life-generated } \\
\text { risks }\end{array}$ & $\mathrm{n}=6$ \\
& & $\begin{array}{c}\text { Escalated partner-generated } \\
\text { risks }\end{array}$ & $\mathrm{n}=3$ \\
\hline
\end{tabular}

were limited but were still supportive as the shelter initially worked through what social distancing would mean for program participants. She stated, "We kind of weren't able to go many places for about a week. It was kind of on lockdown, but we got through it because the staff basically went out and got what we needed, so it was fine." The participant further described her relationship with the staff, stating, "they're super sweet."

Elizabeth, another participant, shared about living in the urban shelter and how it provided her a safe place to live and help her to achieve her goals saying,

Being in the shelter, they're helping me, giving me a place for me and my kids to lay without me having to hustle up some money every day. They're able to eat.........Pretty much, they're going to help me with housing. I got job interviews, so it's pretty much given me comfort knowing we have somewhere to sleep every night while I do what I'm supposed to do.

Table 1 Themes and subthemes by category

\begin{tabular}{|c|c|c|c|c|}
\hline Category & Theme & Definition & Subtheme & Definition \\
\hline \multirow{2}{*}{$\begin{array}{l}\text { Experi- } \\
\text { ences } \\
\text { with } \\
\text { service } \\
\text { providers }\end{array}$} & $\begin{array}{l}\text { Varying } \\
\text { levels of } \\
\text { support }\end{array}$ & $\begin{array}{l}\text { Describes positive and negative expe- } \\
\text { riences of support }\end{array}$ & & \\
\hline & Isolation & $\begin{array}{l}\text { Describes both the negative and } \\
\text { positive effects of isolation during } \\
\text { quarantine }\end{array}$ & & \\
\hline \multirow{2}{*}{$\begin{array}{l}\text { Impact of } \\
\text { COVID- } \\
19 \text { on } \\
\text { daily } \\
\text { lives }\end{array}$} & Escalation & $\begin{array}{l}\text { Describes the escalation of violence, } \\
\text { mental health issues, or adverse life } \\
\text { circumstances }\end{array}$ & Escalated life-generated risks & $\begin{array}{l}\text { Describes factors that are external to but } \\
\text { build upon and compound the violence } \\
\text { within intimate relationships }\end{array}$ \\
\hline & & & Escalated partner-generated risks & $\begin{array}{l}\text { Describes risks created explicitly by an } \\
\text { abusive partner }\end{array}$ \\
\hline
\end{tabular}


Although many participants reported that they felt supported while receiving services, some felt supported despite the limitations imposed on the shelter, while others did not feel as supported due to the COVID-19 restrictions. One participant from the rural and one from the urban shelter also described receiving limited support from service providers as they tried to navigate COVID-19 rules. Emily, a participant living at the rural shelter, stated, "Right now because of the quarantine, [the agencies] can't [do as much]. But, I mean, they can only do so much, I guess I could say.” Even with the limited support, this participant was understanding of the circumstances surrounding COVID-19 and the limitations that the agency may be facing. Another participant, Cece, who was living in the urban shelter, also discussed the limited support that she received from the agency and echoed how this reminded her of dynamics within her abusive relationship. Cece expressed frustration about not being able to leave the shelter to go where she needed.

Theme 2: Isolation In addition to experiencing varying levels of support, participants discussed varying experiences of being isolated. The participants discussed both positive and negative impacts of COVID-19-related isolation on their lives and experienced isolation as both a protective and risk factor for IPV. Seven of the participants from both the urban and rural shelters discussed feelings of isolation during the pandemic. Two of the participants, both from the urban shelter, discussed their frustrations with not being able to leave the shelter to obtain items they needed due to the stay-athome order. Both women stated that they felt like they were back with their abuser. Shy stated, "It kind of makes me feel like I'm back at home." In Cece's case, she contemplated returning to her abusive partner, saying:

[The shelter staff] said we're on quarantine. They say that if it's not an emergency, then, no, we can't just get up and go anywhere. We have to get permission. I feel like I'm back under my abuser's hands. It makes me want to go back home.... [At home] I didn't have what I wanted, but I got the things I needed.

Some participants described how staying in the shelter during the pandemic contributed to their safety (both in terms of their health and safety from violence). They also discussed how being isolated provided an opportunity for introspection. In these instances, the requirements to stay at home in the shelter prevented the participants from being located by their abusive partner and provided an opportunity to focus on healing, learning more about IPV tactics, and focusing on their own safety. Specifically, two participants described positive aspects of not being allowed to leave the shelter, despite the isolation they experienced. Nicole, the participant living in transitional housing associated with the urban shelter, stated that she did not have access to a phone or computer due to COVID-19, and it was helpful for ensuring her safety because no one knew where she was. Lucy, who was living in the rural shelter, shared that COVID-19 forced her to stay inside and provided her with time for introspection. She stated that being forced to stay indoors kept her from "being able to find a new relationship so that maybe I wouldn't fall back into the same cycle of domestic violence."

\section{Category II: Impact of COVID-19 on the Daily Lives of Survivors}

In addition to the experiences of services, while living in the shelter, participants discussed how COVID-19 impacted their daily lives. The participants discussed their experiences both while involved in IPV services as well as reflected back on how COVID-19 impacted the abuse that they experienced prior to entering the shelter. The main theme of escalation and the subthemes within are described below.

Theme: Escalation Participants shared experiences related to how COVID-19 contributed to escalation, mental health issues, adverse life circumstances, and violence. Within the theme of escalation were the subthemes of escalated lifegenerated risks and escalated partner-generated risks. These subthemes were adopted from Davies' and Lyon's (2014) risk analysis framework. Davies and Lyon (2014) define life-generated risks as risks that anyone may face, such as health concerns, unemployment, or bias related to their race or ethnicity. Partner-generated risks include physical and non-physical violence used by abusive partners to enhance dominance and control. Five participants reported experiencing an escalation in life or partner-generated risk.

Life-Generated Risks Life-generated risks related to COVID-19 identified by survivors included mental health concerns, difficulty completing goals while in the shelter, and unemployment. One of the residents from the rural shelter, Emily, reported that not knowing the severity of the virus exacerbated her anxiety stating, "I already have bad anxiety, and it is easy for me to have a panic attack." COVID-19 also added an additional stressor related to securing housing for survivors who had to weigh the risks and benefits of exposing themselves and their children to COVID-19 in order to locate stable and safe housing, especially if the property has not adopted safety protocols (Simmons Starrs, 2020). Nicole, who is living in transitional housing in an urban area, stated:

I really didn't want to bring them out, but I had to. I'm risking myself and my kids to go find somewhere for 
us to stay. But at the same time, we're going to have to sacrifice because we need somewhere to stay.

Limited public transportation also impacted survivors' abilities to reach service goals that required them to travel into the community. Elizabeth, a survivor living at the urban shelter, shared her difficulty accessing transportation, saying, "The buses are horrible now. We tried the bus you need to go downtown, and it's only 14 people on the small buses, and if it's too many people, they just pass you." Elizabeth also highlighted how life-generated risks created by COVID19 could compound batterer-generated risks, sharing that her unemployment related to COVID-19 made her vulnerable to her former partner's abuse. She had previously left her abusive partner when she was pregnant. She shared:

I was working at a restaurant making good tip money, so I was able to pay for a hotel every night, like weekly. Well, when I had my son... they said they were just going to temporarily let me go and then [would] let me come back. After I had my son, I asked if I could come back to work because I was running low on money. But with COVID-19, they can only have a certain amount of people at their store 24/7.

Partner-Generated Risks Several participants reported partner-generated risks related to COVID-19. Shy, an urban shelter resident, stated the abuse she experienced escalated due to COVID-19, stating, "it got worse because he couldn't work. He was home more. He would nick and pick at me, and pick fights". She reported that the stress of stores not having the supplies they needed adding to the tension stating, "Because one of my children is still in diapers and we'd need milk, and the store would be out of that a lot. Every time he got mad; he took it out on me". Similarly, Denise, a survivor living in the rural shelter, hypothesized that the reason the violence started was due to COVID-19. She asserted:

That's why it got domestic. I can't make excuses for it, but I don't know. It's just a major impact because if a person cannot go into a building, or work, or go get a job, and everything's lockdown.

Elizabeth, who lost her job due to COVID-19 reported,

I couldn't go back to that job to get the hotel room. I had to stay at night at my kid's father's [relative's] house. He found out I was there, and that's what put me back into the domestic violence shelter.

\section{Discussion}

The purpose of this study was to explore female survivors' lived-experiences of IPV within the context of COVID-19 and their perceptions of service providers. The pandemic has had a pernicious impact on survivors of IPV that has led to new and increased cases of IPV in families (Campbell, 2020; Davis et al., 2020; Piquero et al., 2021; Rai et al., 2020; Wood et al., 2021). Therefore, understanding the experiences of survivors and their perceptions of service providers is crucial to providing persistent and improved support to this group. Importantly, recommendations stemming from the voices of these survivors can be put to immediate practice as we continue to experience the new realities of the COVID19 pandemic and future planning for new public health emergencies and other disasters.

Survivors shared a range of perspectives related to how they experienced the support they were being provided with by IPV service providers, with some survivors feeling supported by the services and others who felt they were receiving limited support. Some survivors explicitly mentioned an understanding of the limitations related to the stay-at-home orders, while others were less tolerant of the restrictions and their impact on service provision. One possible explanation for these divergent responses could be related to the varying levels of trauma symptoms. Survivors with lower levels of trauma symptoms may be better able to adapt to and manage COVID-19 related restrictions (Horesh \& Brown, 2020; Ohio Domestic Violence Network, 2010; Southhall, 2020). Similarly, some survivors drew connections between the restrictions they experienced within the service context and previous experiences of isolation or coercive control at the hands of their abusive partners. For those survivors, agency responses may have unintentionally triggered traumatic memories and elicited trauma-related responses (Horesh \& Brown, 2020). From the testimony of these survivors, it is evident that the shelter restrictions imposed by the stay-athome orders put in place to protect survivors and staff alikemay have triggered traumatic memories of isolation and control (Ohio Domestic Violence Network, 2010; Southall, 2020). Although IPV literature has found that shelters can inadvertently replicate the abusive dynamics experienced by survivors (Glenn \& Goodman, 2015), COVID-19 may have amplified this phenomenon.

However, some survivors felt that social isolation experienced in relation to the stay-at-home orders functioned as a protective factor against IPV. This effect has been documented prior to COVID 19. Pre COVID-19 research (e.g., Anderson et al., 2012; Eckhardt et al., 2013; Song \& Shih, 2010) shows that survivors frequently report satisfaction with IPV services such as shelter services, citing positive experiences where they felt safe, supported, and experienced increased personal growth (e.g., levels of self-esteem, selfacceptance, and self-efficacy). Further, IPV housing interventions demonstrate effectiveness in reducing exposure to violence (Klein et al., 2021). These were experiences shared by survivors who were sheltering-in-place away from their abusive partner, highlighting the critical role of housing 
supports, emergency shelters, and transitional housing in providing safety for survivors in case of a public health emergency. Many shelters at least temporarily reduced their capacity at the onset of social distancing requirements in order to comply with isolation protocols, impacting the number of survivors without access to safe housing. Given the testimony of survivors in this study related to the role of safe housing in promoting their well-being during COVID-19, planning for future public health emergencies should include efforts to add shelter or housing capacity to meet a potential surge in need while accounting for isolation requirements. Some IPV agencies have utilized hotel rooms for survivors and their children when the shelter has reached capacity due to social distancing requirements (J. Rey, personal communication, February 25, 2021; Snyder, 2020; Usher et al., 2020). As a significant amount of evidence indicates that IPV rates have increased during previous times of disaster, the COVID-19 pandemic should not be viewed as an isolated occurrence that has led to increased violence in the home but as the latest of many public health emergencies that can occur (Anastario et al., 2009; Mahapatra, \& Rai, 2019; Kofman \& Garfin, 2020; Lauve-Moon \& Ferreira, 2017). Thus, it can be concluded that this pattern will continue with future disasters, so it would behoove IPV agencies to establish protocols that will better equip them to serve a larger need in the community (First et al., 2017). Survivors also discussed how COVID-19 increased their life-generated risks and partner-generated risks. The life-generated risks identified by the participants included the exacerbation of existing mental health concerns, including heightened anxiety. Existing pre-COVID-19 research has demonstrated a relationship between disaster post-traumatic stress disorder and major depressive disorder (Galea et al., 2005; Goldmann \& Galea, 2014).

A common experience shared by participants was that their partner's unemployment and the stress of not being able to access essential items added to the tension of the relationship, which participants identified as a catalyst for abuse. This finding is consistent with existing studies that linked unemployment and reduced income to IPV experiences during the COVID-19 pandemic (Anurundan et al., 2020; Campbell, 2020; Davis et al., 2020). These findings are further supported by ample evidence that housing instability, relationships stress, and survivor and partner mental health challenges are all linked to the heightened risk of violence outside of the context of a public health emergency (Capaldi et al., 2012; Kuijpers, 2012; Matjasko et al., 2012).

\section{Limitations}

Despite the utility and timely contribution of this study, it is not without some limitations. First, although the goal of qualitative research is to provide a rich and thick description of the data (Merriam et al., 2019), due to the small sample size, the transferability of findings can be limited (Trochim \& Donnelly, 2008). Findings also stemmed from one question related to COVID-19. Moreover, there were no apparent differences in the experiences of survivors living in rural and urban areas, potentially due to the small sample size. Second, the study was only conducted with participants in a single state at one timepoint in the COVID-19 pandemic, which could also limit the findings, as they reflect a specific set of required lockdown procedures, as well as similar recommendations and technical assistance provided by the state domestic violence coalition. Third, although participant racial demographic information was collected, the participants were not asked whether they were immigrants or if they were facing challenges related to their immigration status, thus, excluding those experiences from this research study. However, despite these limitations, this study contributes to building novel empirical evidence pertaining to service utilization by IPV survivors during the global pandemic.

\section{Implications for Research, Policy, and Practice}

Survivors of IPV continue to face challenges as the COVID19 pandemic unfolds. Therefore, being responsive to their needs and understanding their voices is imperative. Ongoing investigations similar to this study but with additional COVID-19 specific questions are needed across various time points in the pandemic. Additionally, although the focus of the study was not on children, future studies focusing on the intersection of IPV and COVID-19 on children are warranted. Further, more research that examines how a public health emergency can impact survivors and their role as caregivers, trying to ensure the safety and education of their children is needed. Research with larger and more diverse samples is critical as it allows for an analysis of within-group differences, as well as highlights effective strategies being employed by service providers to address unique life-generated risks created by the COVID-19 pandemic. The findings of this study carve a pathway for future researchers to ask questions about safety and the types of additional services or support that survivors may need.

For shelter-residing survivors, feelings of control and support are linked with a wide range of positive post-shelter outcomes, including enhanced long-term economic and physical safety (Sullivan \& Virden, 2017). In the context of COVID-19, some participants discussed a sense of loss of control or support, while others articulated a recognition of the challenges facing shelter staff and a sense of appreciation for the added work that was going into keeping them safe in a new context. Being able to articulate the reasoning behind shelter policies and procedures has been shown to enhance outcomes and promote survivor empowerment (Wood et al., 
2017). Some participants discussed a sense of loss of control or support, while others articulated a recognition of the challenges facing shelter staff and a sense of appreciation for the added work that was going into keeping them safe in a new context. These mixed feelings among participants could call for service providers to provide tailored services depending on participant needs. For instance, the participants who experienced a feeling of lack of control or support could be engaged more through frequent check-ins and socially distant group activities. For others who appreciated the support received at the shelters could also be encouraged to lead activities and/or provide mutual aid and support to those experiencing distress in the shelter setting. Moreover, these findings can be helpful for social workers and others belonging to the helping professions to understand the level of satisfaction among survivors when it comes to service utilization.

The finding that a survivor in transitional housing did not have access to the internet or phone suggests a need for IPV agencies to ensure survivors are able to leverage technology as part of their safety planning as well as for their ability to complete their service goals such as, increase employment opportunities by having the ability to telework. Providing survivors with technology access can also help reduce alienation and isolation that can overcome survivors' living in shelters (Mahapatra \& Rai, 2019; Voth Schrag et al., 2021). As society shifts to a post-COVID-19 reality, agencies will continue to adopt technology-facilitated services. Given the isolation and fear shared by survivors who were living with their intimate partners during the onset of COVID-19, there is a clear call for continued work to understand and implement services that could better reach those survivors. To date, much of the research on the use of technology to support IPV survivors has been focused on using apps, rather than on the use of information communication technology (e.g., cell phones, chat/text) to mediate and facilitate the advocate-survivor relationship (Brignone \& Edleson, 2019). As advocates seek strategies to bridge the support gap during the COVID-19 pandemic and in planning for future public health emergencies, work to understand effective and safe strategies for recreating the in-person advocacy experience using virtual platforms is critical.

Further, community-based service providers are encouraged to partner with researchers and scholars to further the translation of research into practice. This translation can be done by improving or expanding existing services that organizations may not be providing. For instance, participants in the present study indicated the need to find employment opportunities. It would be beneficial if service providers could connect with employment agencies and provide opportunities for survivors to find jobs and become self-reliant (Postmus et al., 2010; Sanctuary for Families [n.d.]). This would also allow survivors to support their children, which was a concern expressed by participants in the present study. Additionally, staff at the shelters could be encouraged to provide support relating to resume building and cover letter writing along with mock job interviews so that participants feel more prepared to apply for jobs.

For several years in the run-up to the COVID-19 pandemic, shortfalls in Victims of Crime Act (VOCA) dollars have been leading to significant reductions in funds available to support services for survivors and, notably, the loss of an important funding safety-net for cash strapped agencies trying to maintain or expand services in the face of mounting need during the pandemic (Sword, 2019). In the face of COVID-19, agencies face reduced fundraising capacity at the same time that the need for service is surging and their capacity to house survivors is (in some cases) halved due to social distancing requirements. Moreover, with the Federal moratorium on evictions ending on June 30, 2021 (Princeton University, 2020), some IPV survivors who have left violent relationships may be forced to cohabitate with their abusive partner or to enter an emergency shelter, if available, in case they do not have sufficient resources to pay their rent or mortgage. The experiences of survivors during the pandemic highlight the need for reestablishing policy frameworks that can fully fund these services with flexible and responsive dollars. This could be achieved partly through re-committing to VOCA, ensuring full funding for a re-authorized Violence Against Women Act, or some other funding scheme,

\section{Conclusion}

This study highlighted the experiences of IPV survivors with service utilization in the context of the COVID-19 pandemic. IPV survivors continue to face excruciating circumstances in this deadly pandemic, and new supportive resources are needed to address these challenges. These solutions must respond to the experiences of survivors as summarized by this study, recognizing that social isolation can be positive for survivors who have found safety but can exacerbate the already precarious situations faced by survivors continuing to reside with an abusive partner. There is an urgent need for us to identify pathways to support IPV survivors and those potentially at risk of experiencing IPV. Given that the pandemic will continue despite and that future public health emergencies may mirror many of the challenges identified in the current context, survivors residing at home will continue to need services, and agencies will need to continue providing support. Listening to survivors' voices and understanding their experiences in the current pandemic opens the door to unique and innovative solutions and ongoing support for survivors. 
Acknowledgements The authors would like to acknowledge Savannah Lindsey for her assistance in the preparation of this manuscript.

Funding This study was supported by funding from The National Institute of Institute for Transportations and Communities.

\section{Declarations}

Conflicts of Interest The authors do not have any conflicts of interest to disclose.

\section{References}

Anastario, M., Shehab, N., \& Lawry, L. (2009). Increased gender-based violence among women internally displaced in Mississippi 2 years post-Hurricane Katrina. Disaster Medicine and Public Health Preparedness, 3(1), 18-26. https://doi.org/10.1097/DMP.0b013 e3181979c32

Anderson, K. M., Renner, L. M., \& Danis, F. S. (2012). Recovery: Resilience and growth in the aftermath of domestic violence. Violence against Women, 18(11), 1279-1299. https://doi.org/10.1177/ 1077801212470543

Anurudran, A., Yared, L., Comrie, C., Harrison, K., \& Burke, T. (2020). Domestic violence amid COVID-19. International Journal of Gynecology and Obstetrics, 150(2), 255-256. https://doi. org/10.1002/ijgo.13247

Arenas-Arroyo, E., Fernandez-Kranz, D., \& Nollenberger. (2020). Can't Leave You Now! Intimate Partner Violence under Forced Coexistence and Economic Uncertainty. IZA Discussion Paper No. 13570. Institute of Labor Economics. https://ssrn.com/abstr act $=3669499$. Accessed 6 May 2021

Avila, A. \& Cardenas, C. (2020). Domestic violence calls spike in Texas cities, while falling in rural areas. Texas Monthly. https://www. texasmonthly.com/news/domestic-violence-pandemic/. Accessed 3 May 2021

Boserup, M. (2020). Alarming trends in U.S. domestic violence during the COVID-19 pandemic. The American Journal of Emergency Medicine. https://doi.org/10.1016/j.ajem.2020.04.077.

Braun, V., \& Clarke, V. (2006). Using thematic analysis in psychology. Qualitative Research in Psychology, 3(2), 77-101. https://doi.org/ 10.1191/1478088706qp063oa

Brignone, L., \& Edleson, J. L. (2019). The dating and domestic violence app rubric: Synthesizing clinical best practices and digital health app standards for relationship violence prevention smartphone apps. International Journal of Human-Computer Interaction, 35(19), 1859-1869. https://doi.org/10.1080/10447318.2019. 1574100

Bureau of Labor Statistics. (2020). Labor force statistics from the Current Population Survey. https://www.bls.gov/cps/cpsaat18. $\mathrm{htm}$. Accessed on 18 June 2021

Campbell, A. M. (2020). An increasing risk of family violence during the Covid-19 pandemic: Strengthening community collaborations to save lives. Forensic Science International: Reports, 2, 100089. https://doi.org/10.1016/j.fsir.2020.100089

Capaldi, D. M., Knoble, N. B., Short, J., \& Kim, H. K. (2012). A systematic review of risk factors for intimate partner violence. Partner Abuse, 3(2), 231-280. https://doi.org/10.1891/19466560.3.2.231

Centers for Disease Control and Prevention. (2018). Preventing intimate partner violence. https://www.cdc.gov/violenceprevention/ intimatepartnerviolence/fastfact.html. Accessed 3 Sept 2020

Congressional Budget Office. (2020). Interim Economic Projections for 2020 and 2021. Congress of the United States Congressional
Budget Office. https://www.cbo.gov/system/files/2020-05/56351CBO-interim-projections.pdf. Accessed 3 Sept 2020

Davies, J. (2017). Victim-defined safety planning: A summary. https:// vawnet.org/sites/default/files/assets/files/2018-07/Victim-DefinedSafety-Planning.1-17.pdf

Davies, J., \& Lyon, E. (2014). Victim Defined Advocacy. Sage.

Davies, L., Ford-Gilboe, M., Willson, A., Varcoe, C., Wuest, J., Campbell, J., \& Scott-Storey, K. (2015). Patterns of cumulative abuse among female survivors of intimate partner violence: Links to Women's Health and Socioeconomic Status. Violence against Women, 2(1), 30-48. https://doi.org/10.1177/10778 01214564076

Davis, M., Gilbar, O., Padilla-Medina, D. (2020). Intimate partner violence victimization and perpetration among U.S. adults during COVID-19: A brief report. https://doi.org/10.1101/2020. 06.08.20125914.

Eckhardt, C. I., Murphy, C. M., Whitaker, D. J., Sprunger, J., Dykstra, R., \& Woodard, K. (2013). The effectiveness of intervention programs for perpetrators and victims of intimate partner violence. Partner Abuse, 4(2), 196-231. https://doi.org/10. 1891/1946-6560.4.2.196

Elo, S., Kääriäinen, M., Kanste, O., Pölkki, T., Utriainen, K., \& Kyngäs, H. (2014). Qualitative content analysis: A focus on trustworthiness. SAGE Open 4(1), https://doi.org/10.1177/ 2158244014522633.

Fernandes-Alcantara, A. L., \& Sacco, L. N. (2020). Domestic violence in the context of COVID-19. (IN11323). Congressional Research Service.

First, J. M., First, N. L., \& Houston, J. B. (2017). Intimate Partner Violence and Disasters: A Framework for Empowering Women Experiencing Violence in Disaster Settings. Affilia Journal of Women and Social Work, 32(3). https://doi.org/10.1177/08861 09917706338.

Galea, S., Nandi, A., \& Vlahov, D. (2005). The Epidemiology of Post-Traumatic Stress Disorder after Disasters. Epidemiologic Reviews, 27(1), 78-91. https://doi.org/10.1093/epirev/mxi003

Glenn, C., \& Goodman, L. (2015). Living with and within the rules of domestic violence shelters: A qualitative exploration of residents' experiences. Violence against Women, 21(12), 14811506. https://doi.org/10.1177/1077801215596242

Godin, M. (2020). How coronavirus is affecting victims of domestic violence. TIME. https://time.com/5803887/coronavirus-domes tic-violence-victims/. Accessed 24 Feb 2021

Goldmann, E., \& Galea, S. (2014). Mental Health Consequences of Disasters. Annual Review of Public Health, 35(1), 169-183. https://doi.org/10.1146/annurev-publhealth-032013-182435

Goodman, L. A., Smyth, K. F., Borges, A. M., \& Singer, R. (2009). When crises collide: How intimate partner violence and poverty intersect to shape women's mental health and coping? Trauma, Violence, \& Abuse, 10(4), 306-329. https://doi.org/10.1177/ 1524838009339754

Guerra, C. (2018). Isolation and domestic violence. https:// breakthesilencedv.org/isolation-and-domestic-violence/. Accessed 3 Sept 2020

Horesh, D., \& Brown, A. D. (2020). Traumatic stress in the age of COVID-19: A call to close critical gaps and adapt to new realities. Psychological Trauma: Theory, Research, Practice, and Policy, 12(4), 331-335. https://doi.org/10.1037/tra0000592

Johns Hopkins University and Medicine Coronavirus Resource Center (2021). Available at: https://coronavirus.jhu.edu/us-map (Accessed on June 16, 2021).

Kantamneni, N. (2020). The impact of COVID-19 pandemic on marginalized populations in the United States: A research agenda. Journal of Vocational Behavior, 119, 103439-103439. https:// doi.org/10.1016/j.jvb.2020.103439 
Klein, L. B., Chesworth, B. R., Howland-Myers, J. R., Rizo, C. F., \& Macy, R. J. (2021). Housing interventions for intimate partner violence survivors: A systematic review. Trauma, Violence, \& Abuse, 22(2), 249-264. https://doi.org/10.1177/1524838019 836284

Koch, T. (1994). Establishing rigour in qualitative research: The decision trail. Journal of Advanced Nursing, 19, 976-986. https://doi.org/10.1111/j.1365-2648.1994.tb01177.x

Kofman, Y., \& Garfin, D. (2020). Home Is Not Always a Haven: The Domestic Violence Crisis Amid the COVID-19 Pandemic. Psychological Trauma, 12(S1), S199-S201. https://doi.org/10.1037/ tra0000866

Kozuch, E. (2020). Report shows LGBTQ people are more likely to be victims of interpersonal violence during COVID-19. https://www. hrc.org/press-releases/report-shows-lgbtq-people-are-more-likelyto-be-victims-of-interpersonal-vi.

Kuijpers, V. (2012). PTSD symptoms as risk factors for intimate partner violence revictimization and the mediating role of victims' violent behavior. Journal of Traumatic Stress, 25(2), 179-186. https://doi.org/10.1002/jts.21676

Lauve-Moon, K., \& Ferreira, R. (2017). An exploratory investigation: Post-disaster predictors of intimate partner violence. Clinical Social Work Journal, 45(2), 124-135. https://doi.org/10.1007/ s10615-015-0572-z

Leat, S. R. (2021). Identifying and measuring environmental stressors in intimate partner violence shelters [Unpublished doctoral dissertation]. The University of Texas at Arlington. http://hdl.handle. net/10106/29823. Accessed 18 June2021

Levitt, B. (2018). Journal article reporting standards for qualitative primary, qualitative meta-analytic, and mixed methods research in psychology: The APA Publications and Communications Board task force report. The American Psychologist, 73(1), 26-46. https://doi.org/10.1037/amp0000151

Longobardi, C., \& Badenes-Ribera, L. (2017). Intimate partner violence in same-sex relationships and the role of sexual minority stressors: A systematic review of the past 10 years. Journal of Child and Family Studies, 26(8), 2039-2049. https://doi.org/10. 1007/s10826-017-0734-4

Mahapatra, N. \& Rai, A. (2019). Every cloud has a silver lining but... "pathways to seeking formal-help and South-Asian immigrant women survivors of intimate partner violence." Health Care for Women International, 40 (11), 1170-1196. https://doi.org/10. 1080/07399332.2019.1641502

Matjasko, J. L., Niolon, P. H., \& Valle, L. A. (2012). The role of economic factors and economic support in preventing and escaping from intimate partner violence. Journal of Policy Analysis and Management, 32(1), 122-128. https://doi.org/10.1002/pam.21666

Merriam, S. B., \& Grenier, R. S. (Eds.). (2019). Qualitative research in practice: Examples for discussion and analysis. Wiley.

Mervosh, S., Lu, D. \& Swales, V. (2020). See which states and cities have told residents to stay at home. N.Y. Times. https://nytimes. com/interactive/2020/us/coronavirus-stay-at-home-order.html. Accessed 3 Sept 2020

Moreira, D., \& Pinto da Costa, M. (2020). The impact of the Covid-19 pandemic in the precipitation of intimate partner violence. International Journal of Law and Psychiatry, 71, 101606-101606. https://doi.org/10.1016/j.ijlp.2020.101606

Neeley, M.T. (2020). Essential and expendable: Gendered labor in the coronavirus crisis. Stanford University. https://gender.stanford. edu/news-publications/gender-news/essential-and-expendablegendered-labor-coronavirus-crisis. Accessed on 6 May 2021

Nix, J., \& Richards, T.N. (2021). The immediate and long-term effects of COVID-19 stay-at-home orders on domestic violence calls for service across six U.S. jurisdictions. 2Police Practice and Research. https://doi.org/10.1080/15614263.2021.1883018.
Nowell, L. S., Norris, J. M., White, D. E., \& Moules, N. J. (2017). Thematic analysis: Striving to meet the trustworthiness criteria. International Journal of Qualitative Methods, 16(1), 1-13. https:// doi.org/10.1177/1609406917733847

Ohio Domestic Violence Network. (2010). Trauma-Informed Care. Ohio Domestic Violence Network.http://www.ncdsv.org/images/ ODVN_Trauma-InformedCareBestPracticesAndProtocols.pdf. Accessed 3 Sept 2020

Ortegon, A. \& Proctor, C. (2020). Calls spiked- then dropped. Domestic abuse survivors, at home with abusers during the pandemic, may be unable to get help. The Texas Tribune. https:// www.texastribune.org/2020/04/24/texas-coronavirus-domesticabuse/. Accessed 3 May 2021

Peitzmeier, S. M., Malik, M., Kattari, S. K., Marrow, E., Stephenson, R., Agénor, M., \& Reisner, S. L. (2020). Intimate partner violence in transgender populations: Systematic review and meta-analysis of prevalence and correlates. American Journal of Public Health (1971), 110(9), e1-e14. https://doi.org/10.2105/AJPH.2020. 305774

Piquero, A., Jennings, W., Jemison, E., Kaukinen, C., \& Knaul, F. (2021). Domestic violence during the COVID-19 pandemic Evidence from a systematic review and meta-analysis. Journal of Criminal Justice, 74, 101806. https://doi.org/10.1016/j.jcrim jus.2021.101806

Piquero, A. R., Riddell, J. R., Bishopp, S. A., Narvey, C., Reid, J. A., \& Leeper Piquero, N. (2020). Staying home, staying safe?: A short-term analysis of COVID-19 on Dallas domestic violence. American Journal of Criminal Justice. https://doi.org/10.1007/ s12103-020-09531-7

Postmus, J. L., Renick, R., Pedroarias, S. M., \& Pentico, K. (2010). Economic Empowerment of Domestic Violence Survivors. VAWnet. https://vawnet.org/material/economic-empowermentdomestic-violence-survivors. Accessed 3 Sept 2020

Princeton University. (2020). COVID-19 and changing eviction policies around the nation. The Eviction Lab. https://evictionlab.org/ covid-eviction-policies/. Accessed 3 May 2021

Rai, A., Perkins, N. \& Grossman, S. (2020). The effects of COVID-19 on domestic violence and immigrant families. Greenwich Social Work Review, 2(1), 84-96. https://doi.org/10.21100/gswr.v1i2. 1161

Salazar, M. (2020). Reports of more serious cases of domestic violence during pandemic. Fox 26 Houston. https://www.fox 26 houston. com/news/reports-of-more-serious-cases-of-domestic-violenceduring-pandemic. Accessed 3 May 2021

Saldaña, J. (2013). The coding manual for qualitative researchers (2nd ed.). SAGE Publications.

Sanctuary for Families (n.d.). Economic empowerment services. https://sanctuaryforfamilies.org/our-approach/client-servi ces/economic-empowerment-services/. Accessed 22 Oct 2020

Snyder, N. (2020). Empty hotel rooms provide safe haven for domestic violence survivors during the pandemic. Huffington Post. https:// www.huffpost.com/entry/empty-hotel-rooms-provide-safe-havenfor-domestic-violence-survivors-during-the-pandemic_n_5eac5 ab2c5b6e5f842971202. Accessed 3 May 2021

Song, L., \& Shih, C. (2010). Recovery from partner abuse: The application of the strengths perspective: Recovery from partner abuse. International Journal of Social Welfare, 19(1), 23-32. https://doi. org/10.1111/j.1468-2397.2008.00632.x

Southhall, A. (2020). Why a drop in domestic violence reports might not be a good sign. The New York Times. https://www.nytimes. com/2020/04/17/nyregion/new-york-city-domestic-violence-coron avirus.html?searchResultPosition=2. Accessed 3 May 2021

Simmons Starrs, N. (2020). Covid-19 safety protocols for apartments and condos. https://www.washingtonpost.com/business/2020/09/ 
14/how-apartments-condos-are-adapting-covid-19-safety-proto cols/. Accessed 3 Sept 2020

Sullivan, C. M., \& Virden, T. (2017). An eight-state study on the relationships among domestic violence shelter services and residents' self-efficacy and hopefulness. Journal of Family Violence, 32(8), 741-750. https://doi.org/10.1007/s10896-017-9930-7

Sword, D. (2019). Shrinking victims fund signals tough times for appropriators. Roll Call. https://www.rollcall.com/2019/03/ 21/shrinking-victims-fund-signalstough-times-for-appropriat ors/. Accessed 3 Sept 2020

Trochim, W. M. K., \& Donnelly, J. P. (2008). Research methods knowledge base ( $3 r d$ ed). Thomson Custom Pub.

Usher, K., Bhullar, N., Durkin, J., Gyamfi, N., \& Jackson, D. (2020). Family violence and COVID-19: Increased vulnerability and reduced options for support. International Journal of Mental Health Nursing, 29(4), 549-552. https://doi.org/10.1111/inm. 12735

Voth Schrag, R., Hairston, D., Brown, M., \& Wood, L. (2021). Advocate and survivor perspectives on the use of technology in help seeking and services with emerging adults in higher education.
Journal of Family Violence, online first publication. https://doi. org/10.1007/s10896-021-00279-0

Wood, L., Heffron, L. C., Voyles, M., \& Kulkarni, S. (2017). Playing by the rules: Agency, policy, procedure in service experience of IPV survivors. Journal of Interpersonal Violence, Advanced Publication Online. https://doi.org/10.1177/0886260517716945

World Health Organization. (2012). Understanding and addressing violence against women. https://apps.who.int/iris/bitstream/handle/ 10665/77432/WHO_RHR_12.36_eng.pdf. Accessed 3 May 2021

Wood, L., Baumler, E., Voth Schrag, R., Guillot-Wright, S., Hairston, D., Temple, J., \& Torres, E. (2021). Don't know where to go for help': Safety and economic needs among violence survivors during the COVID-19 pandemic. Journal of Family Violence, online first publication. https://doi.org/10.1007/s10896-020-00240-7

Publisher's note Springer Nature remains neutral with regard to jurisdictional claims in published maps and institutional affiliations. 